\title{
Bioterrorismo: dados de uma história recente de riscos e incertezas
}

\section{Bioterrorism: data of a recent history of risks and uncertainties}

Dora Rambauske Cardoso ${ }^{1}$

Telma Abdalla de O liveira Cardoso ${ }^{2}$

Abstract Today, bioterrorism is a real threat in the whole world. Considering the actions of bioterrorism by using biological agents capable of promoting great epidemicsand overload in the health systems of any city, state or country, the bioterrorism is not only a health professional concern, but government and military also. This article discusses a bibliographical review done in the LILACS, M ED LINE, SCiELO and REPIDISCA databases, during theperiod of 1997 the2007, thecharacteristics of related national publications to the bioterrorism, the type of biological agents studied, and the existing knowledge in the country to face a bioterrorism event, in order to feed with information the professionals who will act in first reply to the bi oterrorism events and that are essential to reduce the number of victims.

Key words Bioterrorism, Biological warfare, Biological agents
Resumo 0 bi oterrorismo éhojeuma ameaça real em todo o mundo. Considerando-se que as ações de bioterrorismo utilizam agentes biológicos capazes de promover grandes epidemias esobrecarga nos sistemas de saúde de qualquer cidade, estado ou país, o bioterrorismo passa a ser não apenas uma preocupação de governantes e militares, mas também dos profissionais da área da saúde. Este artigo discute, através de uma revisão bibliográfica, nas bases dedados LILACS, M ED LINE, SciELO e REPIDISCA, no período de 1997 a 2007, as características das publicações nacionais relacionadas ao bioterrorismo, o tipo de agentes biológicos estudados e o conhecimento já existente no país para fazer frente a um evento de bioterrorismo, a fim de subsidiar com informação os profissionais que irão atuar em ações de primeira resposta aos eventos de bioterrorismo e que são imprescindíveis para reduzir o número de vítimas.

Palavras-chave Bioterrorismo, Guerra biológica, Agentes biológicos
${ }^{1}$ Centro Tecnológico do

Exército. Avenida das

Américas 28705, Guaratiba.

23020-470 Rio de Janeiro

RJ.dora.cardoso@uol.com.br

2 Fundação Oswaldo Cruz. 


\section{Introdução}

Conhecida desde há muito, a guerra biológica distingue-se do bioterrorismo e muitas vezes se confundiram no curso de história.

O vocábulo "bioterrorismo" foi incluído na linguagem cotidiana de diversos países e do Brasil desde 0 atentado terrorista ocorrido na cidade de $\mathrm{N}$ ova I lorque, no ano de 2001, seguidos de episódios de disseminação de esporos de antraz (esporos de Bacillus anthracis da cepa Ames), através do sistema postal americano, resultando em onzecasos de antraz pulmonar dos quais cinco evoluíram à óbito ${ }^{1}$.

A correta definição do conceito de bioterrorismo pode auxiliar na compreensão deste fenômeno. Segundo o Centers for Disease Control and Prevention (CDC/Estados Unidos), bioterrorismo éa "disseminação deliberada de bactérias, vírus ou outros microorganismos utilizados para causar doença ou morte em populações, animais ou plantas"2. M agalhães descreve bioterrorismo como sendo o uso intencional de microorganismos ou toxinas derivadas de organismos vivos, vírus ou príons causando morte ou doença em pessoas, animais ou plantas. 0 bioterrorismo pode ocorrer por meio de fômites, vetores, animais infectados, produtos de origem animal, vegetal ou doenças emergentes ${ }^{3}$. M orse ${ }^{4}$ inclui na definição do CDC, a palavra "terror", sugerindo que $o$ elemento surpresa e $o$ fato de um ataque de bioterrorismo pode levar horas ou dias para ser descoberto, utilizando-se da dimensão psicológica como uma ferramenta importante para terroristas. Almeida5, concordando com a importância deste componente, afirma em seu artigo que "[...] a ameaça biológica do bioterrorismo é uma história mais de pânico do que de fatos". Radosavljevic ${ }^{6}$ ressalta que o objetivo principal destes atos éa disseminação de medo, pânico, ansiedade e insegurança na população, provocando a perda de confiança nas autoridades governamentais e prejuízos econômicos. Os ataques resultam em doença e morte, destroem o equilíbrio psicológico eemocional da população e expõem os indivíduos à submissão pelo medo. Segundo o $M$ anual de Aspectos $M$ édicos das 0 perações de D efesa Química, Biológica e Nuclear da O rganização do Tratado do Atlântico Norte (OTAN), guerra biológica é descrita como o emprego de agentes biológicos com a finalidade de causar doenças e mortes em pessoas ou animais e danificar plantas ou materiais?

A guerra biológica é fundamentada no contexto de uma ofensiva militar e ataque em massa às populações, quando usados meios para tal. É uma questão de poder militar de Estados nacionais politicamentecentrais, tendo setornado uma possibilidade interessante a partir da primeira metade do século $X X$, quando passou a ser um campo de articulação crescente e potente entre 0 poder militar e a ciência. Assim, diversos países desenvolveram programas ofensivos com a utilização de armas biológicas 5 .7. A literatura especializada descreve diversos tipos de armas biológicas, quevariam de artefatos mais simples como as estacas "pungi" utilizadas na guerra do Vietnã atémísseisintercontinentais.

O bioterrorismo está relacionado a pequenos grupos ou indivíduos que têm como objetivo pre judicar outros indivíduos de uma determinada região ou com uma dada característica, utilizando para isto meios mais simples para disseminação dos agentes biológicos ${ }^{5}$. 0 número de mortes indiscriminadas e a falta decontrolesobreos agentes biológicos disseminados no ambiente são os principais instrumentos do bioterrorismo.

Assim, os agentes biológicos têm sido utilizados pelo homem tanto em operações de guerra biológica quanto em eventos de bioterrorismo.

Almeida ${ }^{5}$ relata a existência, ao longo da história da humanidade, de diversos exemplos da utilização de agentes biológicos com a finalidade de causar doenças ou morte nos inimigos.

Silva ${ }^{8}$ ressalta que um dos exemplos mais antigos encontrado na literatura éa colocação de fezes de animais pelo homem de $N$ eanderthal nas flechas que utilizava, para aumentar o poder letal de suas armas.

Estudos que datam do início do século XV a.C. apontam como o primeiro ataque biológico a introdução deliberada de cepas de antraz no Egito, vitimando o próprio faraó e sendo descrita na Bíblia como a quinta praga 5 .

No século XIV, durante o cerco da cidade de Caffa, Criméia, os tártaros lançaram os cadáveres de seus soldados, infectados pelo agente etiológico da peste, sobre os muros da cidade sitiada, a fim de provocar uma epidemia de peste no inimigo e assim derrotá-los?.

Os espanhóis, ao desembarcarem no M éxico em 1518, trouxeram com eles várias doenças infecciosas, como varíola, sarampo e influenza, às quais a população indígena local nunca havia sido exposta. Conquistadores do império inca, após correlacionarem a varíola com a alta mortalidadeentrea população indígena, enviavam àfrente de suas tropas soldados ou escravos portando lanças com panos de linho impregnados de se creções obtidas de doentes de varíola, além de, 
ao levantar acampamento de determinada área, abandonar objetos contaminados ou oferecê-los aos índios locais ${ }^{10}$.

N a América, em 1763, o exército britânico em guerra contra os franceses enviou cobertores e lenços previamente utilizados em um hospital para pacientes com varíola aos índios Delaware, aliados dos franceses ${ }^{9}$.

O Japão conduziu pesquisas com armas biológicas, na M anchúria, de 1932 até o final da Segunda Guerra Mundial, com os agentes biológicos da peste, antraz, cólera, entre outros ${ }^{9}$.

$\mathrm{N}$ a segunda metade do século $X X$, durante a guerra fria, os Estados Unidos e a então União Soviética, sem dúvida se valendo da experiência acumulada de japoneses e alemães, implantaram programas para o desenvolvimento de armas biológicas, da mesma maneira que o Canadá e o Reino Unido?.

Em resposta à utilização, principalmente de agentes químicos de guerra durante a Primeira Guerra Mundial, esforços diplomáticos internacionais foram dirigidos para limitar a proliferação e o uso das armas de destruição em massa, sendo em 17 de abril de 1925 estabelecido o Protocolo de Genebra, que proibia o emprego na guerra de gases asfixiantes, tóxicos ou similarese de métodos bacteriológicos de guerra. Entretanto, este tratado prevê apenas a proibição do uso dessas armas, mas não proíbe a pesquisa básica, a produção, a posse de armas biológicas ou outras atividades passíveis de serem executadas ${ }^{9,11}$.

Assim, com o objetivo de excluir completamente a possibilidade do uso de armas biológicas, elaborou-se a "Convenção sobre a Proibição do Desenvolvimento, Produção, eEstocagem de Armas Bacteriológicas (Biológicas) e à Base de Toxinas e sua Destruição", ou, simplesmente, Convenção sobre a Proibição de Armas Biológicas (CPAB), que foi o primeiro tratado multilateral de desarmamento a prever a completa eliminação desta categoria de armas de destruição em massa. Aberta simultaneamente para assinaturas em 10 de abril de 1972, em Londres, M oscou e Washington, entrou em vigor em 26 de março de 1975, sendo aprovada no Brasil pelo Decreto Legislativo no 89 e promulgada através do Decreto 77.374, de 1으 de abril de 1976. Conta atualmente com 151 Estados partes e dezesseis Estados signatários ${ }^{11}$.

Com o tratado da CPAB, esperava-se que os agentes biológicos não fossem mais utilizados para fins de guerra ou bioterrorismo, mas eventos ocorridos após a sua promulgação mostraram que não.
Em 1979, ocorreu um surto de antraz em Sverdlovsk, na antiga União Soviética, inicialmente atribuído ao consumo de carne contaminada, que causou grande numero de mortes. Posteriormente, verificou-se que o surto resultou da dispersão de esporos de antraz, sob forma de aerossol, a partir de um acidente ocorrido em umainstalação militar de microbiologia que produzia a bactéria Bacillus anthracis, embora a União Soviética fosse um dos Estados parte da CPAB desde $1975^{12}$.

Em 1984, uma seita, no Oregon (Estados Unidos), utilizou Salmonella typhimurium para contaminar bufês de salada, provocando gastroenterite em aproximadamente 751 pessoas $^{13}$. Em 2001, logo após o ataque terrorista de 11 de se tembro, foram disseminados esporos de antraz, por meio do sistema postal americano, ocasionando 23 casos de antraz, relatados ao CDC/ Atlanta, até 9 de janeiro de 2002, sendo onze casos confirmados de antraz pulmonar e doze casos de antraz cutâneo, dos quais sete casos confirmados e cinco casos suspeitos ${ }^{14}$. Em 2003, na Carolina do Sul (Estados Unidos), na sala de correspondência do escritório do senador americano Bill Frist, foi encontrada ricina, em uma carta endereçada à Casa Branca ${ }^{15}$.

Portanto, a pergunta já não é "se ocorrer?" e sim "quando?" e "o que fazer?". Uma vez que alguns agentes utilizados como armas biológicas necessitam de um período de incubação, não apresentando seus efeitos imediatamente após serem dispersos, um evento de bioterrorismo pode ocorrer silenciosamente, sem nenhum aviso prévio, só sendo percebido quando surgem plantas, animais ou seres humanos doentes ou mortos. Assim, quando as autoridades forem alertadas para a ocorrência de um evento deste tipo, o número de vítimasjá poderá ser expressivo, sobrecarregando os sistemas de saú de e acarretando uma grande demanda de profissionais qualificados para atuar neste tipo de ameaça, quantidades expressivas de medicamentos e vacinas, materiais e equipamentos, além de informações e treinamento adequados ${ }^{16}$.

Desta forma, é de um modo aparentemente inesperado que a saúde pública passa a estar envolvida com um assunto antes de interesse ape nas militar ${ }^{8}$.

N esse sentido, o objetivo desta revisão bibliográfica foi de levantar o número de publicações existentes no país sobre bioterrorismo e analisar o impacto dos eventos de bioterrorismo ocorridos nos Estados Unidos no ano de 2001, nestas publicações. 


\section{Metodologia}

Estudo de revisão bibliográfica realizado entre os anos de 1997 a 2007, utilizando os bancos de dados eletrônicos: Literatura Latino-Americana e do Caribe em Ciências da Saúde (LILACS), Literatura Internacional em Ciências da Saúde (M EDLINE), Scientific Electronic Library O nline (SciELO) e Literatura em Engenharia Sanitária e Ciências do Ambiente(REPIDISCA), disponíveis na Biblioteca Virtual em Saúde (BIREM E).

Osdescritores utilizados inicial menteforam: bioterrorismo e guerra Biológica, refinando-se a pesquisa por meio do idioma português ou através do país de publicação (Brasil).

$\mathrm{Na}$ etapa seguinte, foram utilizados como descritores as doenças cujos agentes biológicos são classificados pelo CDC, como sendo da Categoria $\mathrm{A}$, ou seja, aqueles que causam riscos à segurança nacional por apresentarem alto grau de transmissibilidade, altas taxas de mortalidade, impacto significativo à saúde e à economia, pânico social, necessitando de requisitos específicos de contenção, rígidos, além de monitoramento dos órgãos de saúde pública ${ }^{17}$. N esta categoria, estão os agentes etiológicos de doenças como antraz, tularemia, peste, varíola, botulismo e ebola (febre hemorrágica viral). Assim, os descritores utilizados nesta etapa foram: antraz, tularemia, peste, varíola, botulismo e ebola, junto com o termo terrorismo, de tal modo que apenas as publicações relacionadas ao bioterrorismo fossem selecionadas.

\section{Resultados ediscussão}

$N$ a revisão bibliográfica de periódicos brasileiros sobre bioterrorismo, não foi encontrado, no período entre 1997 e2007, um número significativo de publicações sobre o tema em estudo, se comparada ao número de publicações em revistas internacionais sobre este mesmo tema, no mesmo período de tempo. Isto sinaliza que ainda é pequeno o número de pesquisadores dedicados ao assunto estudado. Alguns fatores podem explicar este resultado, como o fato de alguns profissionais ainda considerarem que o tema em questão não pertenceà saúde pública, mas sim aos órgãos de defesa civis e militares, enquanto outros não acreditam na possibilidade de ocorrência deste tipo de evento no Brasil. Outra razão deste resultado seria a inexistência de casos de bioterrorismo no país, embora existam suspeitas em relação ao surgimento de doenças que causaram princi- palmente prejuízos ao agronegócio, como no caso da disseminação da doença que atacou as plantações de cacau, no sul da Bahia, no período de 1980 a 1990, conhecida por vassoura-de-bruxa³.

$\mathrm{Na}$ LILACS, uma base de dados cuja abrangência se restringe às publicações relativas às $\mathrm{Ci}$ ências da Saúde nos países da América Latina e Caribe, ao se utilizar o descritor bioterrorismo, foram encontrados $28,5 \%$ de publicações em periódicos brasileiros. $\mathrm{Na} M \mathrm{EDLINE}$, que abrange as publicações internacionais, na busca realizada com o mesmo descritor, verificou-se que menos de $1 \%$ dos trabalhos encontrados sobre bioterrorismo pertencem aos periódicos brasileiros. Já no SciELO, uma base de dados cuja abrangência se restringe às publicações relativas às Ciências da Saúde no Brasil, Portugal e alguns países de língua espanhola, ao utilizar o descritor bioterrorismo, $100 \%$ das publicações encontradas pertencem aos periódicos brasileiros, sendo que $50 \%$ foram publicadas na revista Cadernos de Saúde Pública, sugerindo que os profissionais de saúde pública já estão sensibilizados com o tema.

Quanto à grande diferença do número de publicações nacionais em relação às publicações internacionais, observadas tanto na LILACS quanto na MEDLINE, sendo que nesta última ainda de forma mais expressiva, pode ser atribuída a diversos fatores, tais como: (1) a utilização de agentes biológicos em programas de guerra biológica por vários países, como Canadá, França, Alemanha, Japão, Estados Unidos, União Soviética, entreos anos de 1930 e $1940^{15}$, visando obter armas biológicas cada vez mais eficientese desenvolver vacinas e medicamentos para as doenças que estas poderiam causar; (2) atentados de bioterrorismo confirmados, ocorridos em diferentes países e (3) atentados com suspeita de bioterrorismo -ocorrência dediversos trotes com amostras suspeitas de conter agentes biológicos altamente infecciosos.

Diferentemente, o perfil verificado na pesquisa com o descritor bioterrorismo na SciELO devese ao fato de que a maioria das revistas existentes nesta base de dados são nacionais.

A abordagem do tema bioterrorismo nas publicações encontradas em revistas brasileiras é bem diversificada, aparecendo em diversas referências junto com os termos biossegurança e biosseguridade. Chaimovich ${ }^{18}$ correlaciona biosseguridade e bioterrorismo e apresenta três definições diferentes de biosseguridade:

1) uma forma de incrementar as medidas nacionais contra o uso de armas biológicas;

2) uma forma de aumentar e fortalecer os 
esforços nacionais e internacionais para investigar se há, ou não, al guma doença que possa alte rar o sistema social;

3) uma medida para estimular a capacidade internacional de responder, investigar e mitigar os efeitos do uso terrorista de toxinas e armas biológicas.

Valle ${ }^{3}$ definebiosseguridade como "o conjunto de medidas e procedimentos que visam proporcionar ao corpo social e a cada indivíduo o maior grau possível de biossegurança sob aspectos científicos, econômicos, sociais, culturais e morais". Um informe técnico da Agência Nacional de Vigilância Sanitária (ANVISA) ${ }^{19}$ aborda a importância de medidas de biossegurança no combate ao bioterrorismo, como a iniciativa de montar uma rede de laboratórios de nível de biossegurança 3 (NB3) capazes de trabalhar com agentes biológicos como o Bacillus anthracis, utilizado por terroristas nos atentados em 2001 nos Estados Unidos, e com isso aumentar a capacidade do país na área de diagnóstico.

Outra abordagem do tema em estudo pode ser verificada em Kottow ${ }^{20}$, que trata de assuntos como o aparecimento de angústias sociais, que têm como características tanto o pânico social quanto as situações de risco, produzidas por este tipo de evento.

Os agentes biológicos mais citados nas publicações pesquisadas são os causadores de antraz (25\%) edevaríola ( $15 \%$ ). Não foi encontrada nenhuma publicação em periódicos brasileiros referente a casos de bioterrorismo envolvendo agentes de patologias como peste, tularemia, botulismo e ebola.
Os artigos sobre antraz são de diversas modalidades, como revisão, relato de pesquisa, estudo teórico, comunicação, atualização metodológica, editorial, entre outros. Este resultado já era esperado, uma vez que a disseminação deliberada de esporos de antraz foi 0 ato de bioterrorismo de maior repercussão mundial nos últimos anos.

A grande diversidade de abordagens sobre 0 tema em estudo faz com que o assunto bioterrorismo possa ser encontrado em diferentes revistas temáticas, voltadas para às Ciências da Saúde, conforme pode ser verificado na Tabela 1.

$\mathrm{Na}$ base de dados REPIDISCA, uma base de dados que contém referências bibliográficas da literatura de Engenharia Sanitária e Ciências do Ambientenos países da América Latina eCaribe, foram encontradas publicações relevantes para o tema em estudo no cenário nacional, como 0 Decreto no 77.374 , de 1976, quepromulgaa Convenção sobre Armas Biológicas e Toxinas $(C P A B)^{21}$, Decreto ㅇ 4.214, de $2002^{22}$, que versa sobre exportação de bens sensíveis e o Decreto Legislativo no $89^{23}$, de 1972, referente à aprovação do texto da CPAB.

Ressalta-seque existem algumas leis específicas que não estão disponíveis na base de dados acima citada, mas estão acessíveis pela Internet, no sítio do Ministério da Ciência e Tecnologia, como a Lei no 9.112, de 10 de outubro de $1995^{24}$, quedispõesobrea exportação de bens sensíveise serviços diretamente vinculados. No primeiro parágrafo do artigo primeiro desta lei, definemse bens sensíveis como sendo os bens de aplicação bélica, de uso duplo e de uso na área nuclear,

Tabela 1. Publicações nacionais recuperadas na pesquisa, no período de 1997 a 2007.

\begin{tabular}{lc}
\hline \multicolumn{1}{c}{ Revista } & Número de publicações encontradas \\
\hline Cadernos de Saúde Pública & 04 \\
Revista de Saúde Pública & 01 \\
Arquivos Catarinenses de M edicina & 01 \\
Estudos Avançados (USP) & 01 \\
Revista Latino-americana de Enfermagem & 01 \\
Jornal Brasileiro de Patologia e M edicina Laboratorial & 01 \\
Revista da Associação de M edicina Brasileira & 01 \\
Revista Paulista de Pediatria & 01 \\
Pediatria Moderna & 01 \\
Jornal Brasileiro de M edicina & 01 \\
Revista do Instituto de M edicina Tropical de São Paulo & 02 \\
Revista Brasileira de Psiquiatria & 01 \\
Revista Brasileira de Epidemiologia & 01 \\
Diário Oficial da União (Leis, Decretos e Portarias) & 03 \\
\hline
\end{tabular}


química e biológica. No inciso quarto, os bens químicos e biológicos são descritos como aquelesrel evantes para qualquer aplicação bélica eseus precursores. No artigo quarto da mesma lei, é constituída a Comissão Interministerial de Controle de Exportação de Bens Sensíveis, enquanto no artigo quinto estão definidas as responsabilidades da referida comissão, dentro das quais está a elaboração, atualização e divulgação das listas de bens sensíveis. Outra publicação que também pode ser encontrada no sítio em referência é a lista atualizada de bens relacionados à área biológica e serviços diretamente vinculados - Resolução Cibes no 8/2007, de 13 de março de $2007^{25}$.

Em relação à outra expectativa deste estudo, foi encontrado um aumento no número de publicações científicas relativas ao tema, após o ano de 2001, o que já era esperado, pois esteano pode ser considerado como um marco histórico, devido à disseminação de esporos de antraz, via sistema postal americano. Conforme pode ser observado na Tabela 2, 90\% das publicações nacionais encontradas ocorreram após o ano de 2001 , sendo que, dentro destepercentual tem-se, $80 \%$ de $2001,30 \%$ de 2002 e $20 \%$ de 2003 , enquanto as restantes ( $10 \%$ ) são anteriores a este período e fazem referência à legislação nacional sobre a CPAB.

Em relação aos anos de 2006 e 2007, este estudo observou que, nos artigos levantados, a abordagem do bioterrorismo não fica centrada unicamenteem relatos, trazendo à discussão também a possibilidade do uso dual da biotecnologia e de outras áreas novas da ciência, chamando a atenção para a importância cada vez maior da adesão dos países à Convenção sobre a Proibição de Armas Biológicas e Toxinas.

Devido à existência de programas de guerra biológica e de diversos episódios, tanto de trotes quanto de casos reais de bioterrorismo, é cada vez maior o número de artigos internacionais sobre o tema em estudo.

Do ponto de vista histórico, pode-se notar que os primeiros programas de guerra biológica, na antiguidade, utilizaram estratégias de sabotagem, muito semelhante ao bioterrorismo. Entretanto, durante a guerra fria, os agentes de guerra biológica foram desenvolvidos como armas estratégicas em larga escala, com a possibilidade de serem disseminados utilizando-se, inclusive, mísseisintercontinentais ${ }^{26}$.

Assim, evidências substanciais sugerem quea Alemanha foi o primeiro Estado nacional a iniciar o desenvolvimento de um programa deguerra biológica durante a Primeira Guerra M undial, no qual foram produzidos os agentes etiológicos do antraz (B. anthracis) e do mormo (Pseudomonas mallei). Entretanto, seu programa biológico ofensivo, propriamente dito, permaneceu precário e rudimentar, levando-os a se especializarem em agentes químicos, criando um ambicioso programa de armas químicas durante a primeira e segunda guerras mundiais. Entre 1932 e 1945, 0 Japão conduziu diversas pesquisas biológicas na M anchúria. Os Estados Unidos iniciaram seu programa de guerra biológica em 1942, sendo expandido durante a Guerra da Coréia (19501953), tendo sido interrompido em 1969 no governo do presidente Nixon ${ }^{3}$. Inspeções realizadas no I raque em 1991, após a Guerra do Golfo, obtiveram informações referentes ao programa de armas biológicas desenvolvido neste país, no período de 1985 a 1991; com a bactéria B. anthracis, toxina botulínica e aflatoxina ${ }^{27}$. Após 0 colapso da União Soviética, Boris Yeltsin, então Presidente da Rússia, admitiu, em maio de 1992, a existência de uma instalação na cidade de Sverdlovsk, onde ocorreu o acidente com antraz em

Tabela 2. Histórico evolutivo das publicações nacionais sobre bioterrorismo no período de 1997 a 2007.

\begin{tabular}{lcc}
\hline \multicolumn{1}{c}{ Ano de publicação } & Número de publicações & Percentual publicações/ano \\
\hline antes de $2001^{*}$ & 02 & $10 \%$ \\
2001 & 02 & $10 \%$ \\
2002 & 06 & $30 \%$ \\
2003 & 04 & $20 \%$ \\
2004 & 00 & $0 \%$ \\
2005 & 04 & $20 \%$ \\
2006 & 01 & $5 \%$ \\
2007 & 01 & $5 \%$ \\
\hline
\end{tabular}

\footnotetext{
*Informações referentes à legislação nacional.
} 
1979, na qual parte do programa soviético de desenvolvimento dearmas biológicas foi realiza$\mathrm{do}^{28}$. A maioria desses programas foi interrompida após estes países tornarem-se signatários da Convenção para a Proibição de Armas Biológicas e Toxinas (CPAB).

Em relação aos atentados de bioterrorismo, um dos mais descritos na literatura é o episódio de contaminação em bufês de salada de restaurantes, no Oregon, em 1984, causado por uma seita religiosa, que utilizou Salmonella typhimurium, afetando cerca de 751 pessoas $^{13}$. Entretanto, os mais famosos são os ataques com antraz em 2001 e com ricina em 2003 ${ }^{14,15}$. Podem ainda ser relatadas as tentativas de bioterrorismo, felizmente sem sucesso, do líder japonês de uma seita religiosa, Aum Shinrikyo, responsável pelo ataque com gás Sarin no metrô de Tóquio, em 1995. O grupo Aum Shinrikyo tinha a intenção de disseminar esporos de antraz e toxina botulínica, além do vírus ebola, obtido no Zaire, em $1992^{29}$.

Nos trotes com amostras suspeitas de conter agentes biológicos al tamenteinfecciosos, relatamse, pelo menos, dois casos como exemplo. Um deles ocorreu em 1992, na Virgínia (Estados Unidos), quando um homem foi preso por aspergir sobre seus colegas de quarto um líquido que ele declarava ser antraz. 0 outro evento aconteceu em 1997, no edifício no qual se situava a Associação B'nai B'rith, em Washington (Estados Unidos), onde foi entregue um pacote contendo um líquido vermelho e uma placa de Petri, acompanhados de um bilhete com os dizeres "Anthracis Yersinia". Em ambos os casos, as amostras analisadas foram negativas tanto para Bacillus anthracis quanto para Yersinia pestis. Entretanto, provocaram pânico nos locais dos acontecimentos, sendo necessário a adoção de uma série de medidas de segurança e contenção, com o bloqueio do acesso a determinadas áreas e a vacinação de um número razoável de pessoas, al go desnecessário, custoso e que pode ocasionar efeitos adversos ${ }^{30}$.

As diferentes abordagens ea variedade de periódicos onde foram encontradas as publicações demonstram a importância da interdisciplinaridade que engloba 0 assunto, uma vez que nos atos de bioterrorismo há a necessidade do envolvimento de diversas áreas, tais como saúde, segurança, defesa, informação, comunicação, entre outras, e também da atuação dos vários órgãos governamentais responsáveis, nas esferas municipais, estaduais e federais, sendo imprescindível uma atuação conjunta, interligada e sistêmica.

Os artigos têm grande impacto para a atualização dos profissionais que atuarão no diagnós- tico clínico enaidentificação laboratorial do agente, cujos resultados precisam ser obtidos de forma rápida e precisa. M ais uma vez, faz-se necessário utilizar como exemplo a disseminação dos esporos de antraz, nos Estados Unidos, em 2001. 0 bacilo do antraz pode causar três tipos de infecções diferentes, cutânea, respiratória e gastrointestinal. Como o bacilo pode esporular, a forma deinfecção mais comum encontrada nos eventos de bioterrorismo é a respiratória, que é a forma mais grave da doença edeidentificação maisfácil.

Destaca-se um artigo, de atualização metodológica, publicado em 2003, em queo autor descreve os métodos desenvolvidos e utilizados com sucesso nos laboratórios da Fiocruz, em 2001, no processamento de seiscentos materiais contendo pós suspeitos de conterem a bactéria Bacillus anthracis, encontrados em diferentes ambientes e circunstâncias. Em nenhuma das amostras analisadas foi detectada a presença de Bacillus anthra$\mathrm{cis}^{31}$. Este artigo confirma o impacto que os atentados terroristas, ocorridos nos Estados Unidos, neste ano, tiveram no Brasil. Trotes como estes ocorreram também nos Estados Unidos. Cabe ressaltar queno Brasil não existeregistro decasos da doença em humanos. Atualmente, o risco de se contrair a doença é mínimo ${ }^{32}$.

Já a varíola é uma doença que também aparece de forma expressiva neste estudo. Alguns artigos descrevem a história da varíola ao longo dos séculos, sempre causando grandes epidemias, dizimando populações não imunizadas eainda sua utilização como arma biológica em diversos episódios ${ }^{8,33}$. Outra publicação aponta para 0 alto potencial de risco do vírus ser utilizado por grupos terroristas, alegando evidências de que algumas nações ou grupos poderiam possuir estoques clandestinos deste agente biológi$\mathrm{CO}^{34}$. Ressaltam-se também algumas discussões sobre o desenvolvimento de novas vacinas e de novos medicamentos antivirais, assim como a viabilidade da imunização da população. Estes artigos demonstram a preocupação dos pesquisadores com a possível disseminação deliberada do vírus. Esta apreensão se deve ao fato da varíola ter sido responsável por epidemias devastadoras atérecentementee sua erradicação ter ocorrido por força de uma campanha mundial de vacinação, tendo sido a primeira doença a ser erradicada por ação humana deliberada. A reintrodução da varíola determinaria um grande número dedoentes, uma vez que mais de $40 \%$ da população mundial nunca foi vacinada eo restanteapresenta imunidade declinante ${ }^{8}$. Outro fato observável em relação aos trabalhos encontrados é a 
divergência sobre o grau de letalidade e a disseminação da doença, caso o vírus viessea ser liberado por meio de um ato terrorista ${ }^{33,34}$.

Embora doenças como peste e botulismo também sejam classificadas pelo CDC como Categoria A, são doenças existentes no Brasil, cujos agentes etiológicos podem ser rapidamente identificados em laboratórios especializadose preparados para esta finalidade. $\mathrm{N} o$ caso da peste, o Brasil possui uma rede de laboratórios de saúde pública nos estados, equipados e capacitados, além de um laboratório de referência nacional, localizado em Recife (Centro de Pesquisas Aggeu M agalhães - CPqAM /Fiocruz).

Atual mente, existem duasáreas principais de focos naturais de peste no país: o Nordeste (região semiárida do Polígono das Secas, abrangendo vários estados, o Vale do Jequitinhonha e 0 Vale do Rio Doce) e o Sudeste (região da Serra dos Órgãos, nos limites dos municípios de Teresópolis, Sumidouro e N ova Friburgo). De 1983 a 2000, foram notificados 487 casos humanos de peste no país, sendo que mais de $50 \%$ dos casos ocorreram na Bahia ${ }^{32}$. A manifestação clínica da peste mais comum no Brasil é a peste bubônica, que quando não tratada possui uma taxa de letalidade de $50 \%$, diferindo das formas pneumônica esepticêmica, mais comuns em episódios de bioterrorismo, cujas taxas de letalidade são próximas a $100 \%$.

Já o botulismo difere da peste por ser uma doença de distribuição mundial, com casos esporádicos ou surtos familiares, em geral relacionados à produção e conservação de alimentos de maneira inadequada. No Brasil, foram notificados 66 casos suspeitos de botulismo entre $1999 \mathrm{e}$ 2006, apresentando taxa de letalidade, nos últimos quatro anos, de $28 \%$. No Brasil, o Instituto Adolfo Lutz éum dos laboratórios de referência do M inistério da Saúde para análise de amostras suspeitas de botulismo.

\section{Consideraçõesfinais}

Este trabalho mostra que, embora ainda existam poucas publicações nacionais relacionadas à bioterrorismo, alguns pesquisadores brasileiros já demonstram a preocupação com o assunto, principalmente depois dos atentados de bioterrorismo ocorridos nos Estados Unidos, com esporos de antraz, o que podeser confirmado pelo número de publicações nacionais encontradas após 0 ano de 2001 , que representa $90 \%$. Contudo, muitas destas publicações são editoriais, artigos de opinião, sendo verificados poucos artigos de re- visão, diferindo das modalidades dos artigos internacionais en contrados nas bases de dados pesquisadas, que trazem uma grande quantidade de informação, seja na forma de artigos de revisão, seja na forma de artigos inéditos.

Destaca-se também a importância dada em al guns artigos à correlação entre bioterrorismo e a biossegurança, demonstrando o quanto o conhecimento das medidas de biossegurança éimportante em vários aspectos da atuação dos profissionais em eventos de bioterrorismo, como na proteção individual e coletiva, contenção deáreas, procedimentos de descontaminação, avaliação de risco, entre muitos outros.

Verificou-se, neste estudo, a existência de leis e decretos tratando da CPAB, o que demonstra o interesse do poder público brasileiro em promover a implementação de acordos e de tratados internacionais sobre o desarmamento enão proliferação de armas de destruição em massa, bem como o controle de transferências (importação e exportação) de bens a elas associados.

Este estudo também verificou a importância dada ao tema por muitos profissionais e pesquisadores, não apenas da área de ssaúde pública. 0 levantamento de informações específicas e verificação dos agentes biológicos, com maior potencial para utilização em eventos de bioterrorismo, indicou que, na sua maioria, já são conhecidos.

Entretanto, ainda existem muitas informações que podem ser estudadas, como o desenvolvimento de fármacos e imunobiológicos, assim como kits diagnósticos que permitam a rápida identificação dos agentes biológicos, o queé imprescindível para a administração correta de medicamentos e vacinas.

Como vários agentes biológicos que possuem potencial parautilização em bioterrorismo podem ser transmissíveis, as medidas de contenção, de descontaminação e uso de equipamentos de proteção individual ecoletivos são de extrema importância para evitar que os profissionais envolvidos nestetipo deevento sejam contaminadosou infectados, aumentando o número de vítimas.

O Brasil está inserido no processo de globalização mundial epara tanto necessita de considerar o bioterrorismo como uma ameaça real e a melhor forma de combatêlo é através da socialização de informações, disseminação do conhecimento e capacitação de todos os profissionais que são responsáveis por atuar em situações de primeira resposta neste tipo de evento, de forma a reconhecer com facilidade um evento de bioterrorismo e identificar a doença através de diagnóstico clínico preciso, permitindo o tratamento das vítimas de forma eficaz. 


\section{Colaboradores}

DR Cardoso participou da pesquisa, análise, interpretação dos resultados e concepção/redação do artigo e TAO Cardoso participou da concepção, metodologia e revisão final do artigo.

\section{Referências}

1. Inglesby TV, O'Toole T, Henderson DA, Bartlett JG, Ascher MS, Eitzen E, Friedlander AM, Hauer J, McDade J, Osterholm MT, O'Toole T, Parker G, Perl TM, Russell PK, Tonat K. Anthrax as a biological weapon. JAM A 2002; 287(17):2236-2252.

2. Centers for Disease Control and Prevention. Bioterrorism. [online] [acessado 2007 nov 11]. Disponível em: http://www.bt.cdc.gov/bioterrorism/ overview.asp

3. Pragas e tráfico de material biológico em debate. Revista do Conselho Regional de Engenharia, Arquitetura e Agronomia da Bahia [periódico na Internet] 2006. Disponível em: http://www.creaba.org.br/Artigo/102/Biosseguranca-Pragas-e-trafico-de-material-biologicoem-debate.aspx

4. Morse SS. Biological and chemical terrorism. Technology in Society 2003; 25:557-563.

5. Almeida ME. Guerra e desenvolvimento biológico: o caso da biotecnologia e da genômica na segunda metade do século XX. Rev. bras. epidemiol. 2006, 9(3):264-282.

6. Radosavljevic V, Jakovljevic B. Bioterrorism - Types of epidemics, new epidemiological paradigm and levels of prevention. Public Health 2007; 121:549-557.

7. North Atlantic Treaty Organization. Field Manual (FM) 8-9 - NATO Handbook on the Medical Aspects of NBC Defensive Operations. Washington, D.C.: NATO; 1996.

8. Silva LJ. Guerra biológica, bioterrorismo e saúde pública. Cad Saude Publica 2001; 17(6):1519-1523.

9. Christopher GW, Cieslak TJ, Pavlin JA, Eitzen EMJ. Biological warfare: a historical perspective. JAM A 1997; 278(5):412-417.

10. Diomedi PA. La guerra biológica en la conquista del nuevo mundo: una revisión histórica y sistemática de la literatura. Rev Chil Infect 2003; 20(1):19-25.

11. Brasil. Ministério da Ciência e Tecnologia. [online]. [acessado 2008 fev 15]. Disponível em: http:// www.mct.gov.br/index.php/content/view/42037.html

12. M eselson M, Guillemin J, Hugh-Jones M, Langmuir A, Popova I, Shelokov A, Yampolskaya O. The Sverdlovsk anthrax outbreak of 1979. Science 1994; 266:1202-1208.

13. Torok TJ, Tauxe RV, Wise RP, Livengood JR, Sokolow $R$, M auvais $S$, Birkness KA, Skeels M R, Horan JM, Foster LR. A large community outbreak of salmonellosis caused by intentional contamination of restaurant salad bars. JAM A 1997; 278(5):389-395.

14. Mina B, Dym JP, Kuepper F, Tso R, Arrastia C, Kaplounova I, Faraj H, Kwapniewski A, Krol CM, Grosser M, Glick J, Fochios S, Remolina A, Vasovic L, M oses J, Robin T, DeVita M, Tapper ML. Fatal inhalational anthrax with unknown source of exposure in a 61-year-old woman in New York City. JAM A 2002; 287(7):858-862.

15. Audi J, Belson M, Patel M, Schier J, Osterloh J. Ricin poisoning: a comprehensive review. JAM A 2005; 294(18):2342-2351.

16. Roffey R, Lantorp K, Tegnell A, Elgh F. Biological weapons and bioterrorism preparedness: importance of public-health awareness and international cooperation. Clin Microbiol Infect 2002; 8:522-528. 
17. Centers for Disease Control and Prevention. Bioterrorismo. [online] [acessado $2008 \mathrm{fev} 15$ ]. Disponível em: http://www.bt.cdc.gov/agent/agentlistcategory.asp\#a

18. Chaimovich $\mathrm{H}$. Biosseguridade. Estudos Avançados 2005; 19(55):261-269.

19. Agência Nacional de Vigilância Sanitária (Anvisa). Biossegurança. Rev Saude Publica 2005; 39(6):989991.

20. Kottow M. Bioterrorismo, biodefesa, bioética. Cad Saude Publica 2003; 19(1):297-303.

21. Brasil. Decreto no 77.374 de 1 de abril de 1976. Promulga a Convenção sobre a Proibição do Desenvolvimento, Produção e Estocagem de Armas Bacteriológicas (Biológicas) e à Base de toxinas e sua Destruição. Diário O ficial da União 1976; 13 abr.

22. Brasil. Decreto n 4.214 de 30 de abril de 2002. Define a competência da Comissão Interministerial de Controle de Exportação de Bens Sensíveis, de que trata a Lei $n$ 0 9.112, de 10 de Outubro de 1995, e dá outras providências. Diário Oficial da União 2002; 2 mai.

23. Brasil. Decreto Legislativo no 89 de 5 de dezembro de 1972. Aprova o texto da Convenção sobre a Proibição do Desenvolvimento, Produção e Estocagem de Armas Bacteriológicas (Biológicas) e à Base de Toxinas e sua Destruição, concluída em Londres, Washington e Moscou, 10 de abril de 1972. Diário Oficial da União 1972; 6 dez.

24. Brasil. Lei $n 09.112$ de 10 de outubro de 1995. Dispõe sobre a Exportação de Bens Sensíveis e Serviços Diretamente Vinculados. Diário O ficial da U nião 1995; 11 out.

25. Brasil. Resolução Cibes no 8/2007 de 13 de março de 2007. Lista de Bens Relacionados à Área Biológica e Serviços Diretamente vinculados. Diário Oficial da União 2007; 1 mar.
26. Roffey R, Tegnell A, Elgh F. Biological warfare in a historical perspective. Clin Microbiol Infect 2002; 8:450-454.

27. Zilinskas RA. Iraq's biological weapons: the past as future? JAM A 1997; 278(5):418-424.

28. Rio-Chiriboga C, Franco-Paredes C. Bioterrorismo: un nuevo problema de salud pública. Salud Pública de M éxico 2001; 43(6):585-588.

29. DaSilva EJ. Biological warfare, bioterrorism, biodefense and the biological and toxin weapons convention. EJB 1999; 2(3):109-139.

30. Keim M, Kaufmann AF. Principles for emergency response to bioterrorism. Ann Emerg M ed 1999; 34(2):177-182.

31. Rabinovitch L, Lorenço MC. Bacillus anthracis, pós e bioterrorismo. J Bras Patol M ed Lab 2003; 39(1):49.

32. Brasil. Ministério da Saúde. Guia de Vigilância Epidemiológica. 6a ed. Brasília: MS; 2005.

33. Levi GC, Kallás EG. Varíola, sua prevenção vacinal e ameaça como agente de bioterrorismo. Rev Assoc M ed Bras 2002; 48(4):357-362.

34. Schatzmayr HG. A varíola, uma antiga inimiga. Cad Saude Publica 2001; 17(6):1525-1530.

Artigo apresentado em 30/05/2008

Aprovado em 05/11/2008

Versão final apresentada em 11/12/2008 